\title{
Essential Role of D1 But Not D2 Receptors in the NMDA Receptor- Dependent Long-Term Potentiation at Hippocampal-Prefrontal Cortex Synapses In Vivo
}

\author{
Hirac Gurden, ${ }^{1}$ Masatoshi Takita, ${ }^{2}$ and Thérèse M. Jay ${ }^{1}$ \\ ${ }^{1}$ Neurobiologie de l'Apprentissage, de la Mémoire et de la Communication, Centre National de la Recherche Scientifique, \\ Unité Mixte de Recherche 8620, 91405 Orsay, France, and 2Neuroinformatics Laboratory, National Institute of Bioscience \\ and Human Technology, Tsukuba, Ibaraki, 305-8566, Japan
}

An intact mesocortical dopaminergic (DA) input to the prefrontal cortex (PFC) has been reported to be necessary for long-term potentiation (LTP) to occur at hippocampal-prefrontal cortex synapses. Here, we investigated the role of D1 and D2 receptors in this NMDA receptor-dependent LTP. Local infusion of the D1 agonist SKF81297 at an optimal dose induced a sustained enhancement of hippocampal-PFC LTP, whereas the D1 antagonist SCH23390 caused a dose-related impairment of its induction. The D1 agonist effect was mimicked by infusion of a low dose of the adenylyl cyclase activator forskolin, whereas LTP was severely attenuated with a protein kinase $A$ inhibitor, Rp-cAMPS. To further assess the complex interplay between
DA and NMDA receptors, changes in extracellular DA levels in the PFC were estimated during LTP, and a significant increase was observed immediately after tetanus. Taken together, these data suggest that D1 but not D2 receptors are crucial for the DA control of the NMDA receptor-mediated synaptic response on a specific excitatory input to the PFC. The interactions of these receptors may play a crucial role in the storage and transfer of hippocampal information in the PFC.

Key words: prefrontal cortex; dopamine; synaptic plasticity; hippocampus; SCH23390; SKF81297; sulpiride; Rp-cAMPS; forskolin
A critical stage of dopamine (DA) and D1 receptor stimulation appears to be necessary for a proper performance in prefrontal cortex-related cognitive tasks like working memory and attentional functions (Williams and Goldman-Rakic, 1995; Granon et al., 2000). In the rat, D1 receptors (mRNA expression) are mostly localized in deep layers V-VI of the prefrontal cortex (PFC), whereas D2 receptors are distributed in superficial and deep layers with lower expression (Gaspar et al., 1995). Neurons located in deep layers and possessing D1 and D2 receptors are output neurons, thus suggesting how DA could affect cortical and subcortical transmission (Gaspar et al., 1995; Lu et al., 1997).

A number of electrophysiological data have pointed out the complex action (excitatory or inhibitory) of DA in pyramidal PFC neurons but have also outlined that the action of DA is dependent on the synaptic strength driven by excitatory inputs on PFC neurons (for review, see Yang et al., 1999). DA terminals in the $\mathrm{PFC}$ are in close proximity to glutamatergic afferents rising from the hippocampal formation (Carr and Sesack, 1996). In vivo, synapses of the hippocampal-PFC fiber pathway can be regulated up and down, expressing potentiation, depression, or depotentiation of synaptic efficacy, and highly specific patterns of afferent activation are responsible for these different forms of plasticity (Jay et al., 1995; Burette et al., 1997; Takita et al., 1999). Furthermore, these glutamatergic afferents to the PFC are undoubtedly implicated at least in short-term memory processes (Floresco et al., 1997; Jung et al., 1998).

\footnotetext{
Received June 19, 2000; revised Aug. 9, 2000; accepted Aug. 24, 2000.

This study was supported by grants from Centre National de la Recherche Scientifique, "Fondation pour la Recherche Médicale", "Fondation Cino Del Duca", and Special Coordination Funds for Promoting Science and Technology (Accelerated Basic Research) from Japan's Science and Technology Agency.

Correspondence should be addressed to Dr. Jay, Neurobiologie de l'Apprentissage, de la Mémoire et de la Communication, Centre National de la Recherche Scientifique, Unité Mixte de Recherche 8620, Université Paris Sud, Bat. 446, 91405 Orsay, France. E-mail: tm.jay@ibaic.u-psud.fr.

Copyright (C) 2000 Society for Neuroscience $0270-6474 / 00 / 200001-\bullet \$ 15.00 / 0$
}

We recently reported that an intact mesocortical DA input to the PFC is necessary for hippocampal-PFC long-term potentiation (LTP) to occur (Gurden et al., 1999). Whereas stimulation of the ventral tegmental area (VTA) at a frequency known to evoke DA overflow in the PFC produces a long-lasting enhancement of the magnitude of hippocampal-PFC LTP, a depletion of $>50 \%$ of cortical DA levels induced a dramatic decrease in this LTP. To obtain further insights into the complex action of DA in this circuit, we examine whether potentiation of the hippocampalPFC pathway increases extracellular DA levels in the PFC in vivo and whether both D1 and D2-like receptors could modulate hippocampal-PFC synaptic plasticity. Additionally, as protein kinase A (PKA) plays a key role in the induction of hippocampalPFC LTP (Jay et al., 1998), we explore further whether the cAMP-PKA pathway plays a role in the modulatory action of DA on cortical synaptic plasticity. Our findings provide strong support for an important role of D1 receptors in modulating hippocampal-PFC plasticity and suggest that DA through D1 receptors could affect the storage of hippocampal information in the PFC or the transfer of such information to output regions of the PFC.

This article is published in The Journal of Neuroscience, Rapid Communications Section, which publishes brief, peer-reviewed papers online, not in print. Rapid Communications are posted online approximately one month earlier than they would appear if printed. They are listed in the Table of Contents of the next open issue of JNeurosci. Cite this article as: JNeurosci, 2000, 20:RC106 (1-5). The publication date is the date of posting online at www.jneurosci.org.

http://www.jneurosci.org/cgi/content/full/4692 


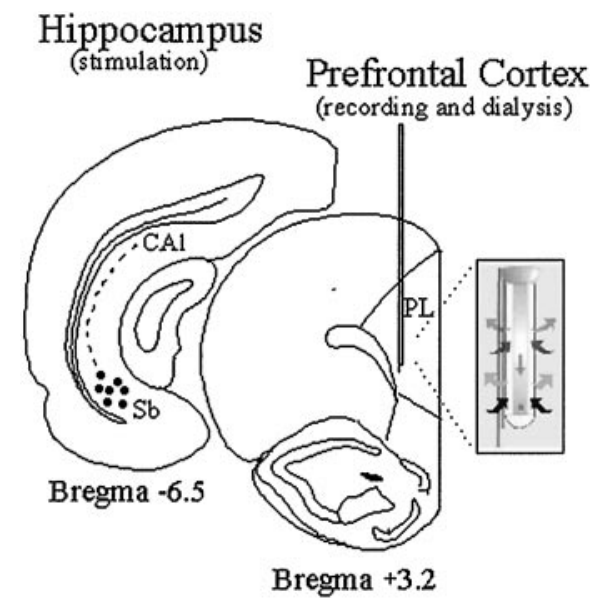

Figure 1. Schematic diagram representing the location of the microdialysis probe with external recording electrodes in the prelimbic area $(P L)$ and the stimulating electrode in the ventral hippocampus. Black spots represent overlapping placements of stimulating sites. $S b$, Subiculum.

\section{MATERIALS AND METHODS}

Electrophysiology. Male Sprague Dawley rats (280-380 gm) were anesthetized with sodium pentobarbital $(60 \mathrm{mg} / \mathrm{kg}$, i.p.) and placed in a stereotaxic frame with body temperature maintained at $37^{\circ} \mathrm{C}$. The procedures were performed in strict accordance with French Agriculture and Forestry Ministry (decree 874848, license A91429) prerogatives. A concentric bipolar stimulating electrode was placed in the CA1/subicular region of the ventral hippocampus (6.3-6.8 posterior to bregma; 5.5 lateral; 4.0-5.8 mm below pial surface). Recording electrodes (64 $\mu \mathrm{m}$ diameter, two nickel-chrome wires) fixed to a microdialysis probe (shorter electrode, same level as the tip of the probe; longer electrode, $200 \mu \mathrm{m}$ deeper; Fig. 1) were slowly lowered into the prelimbic area of the PFC (3.0-3.3 mm anterior to bregma; $0.7-1.0 \mathrm{~mm}$ lateral; $2.8-3.4 \mathrm{~mm}$ below pial surface). The microdialysis probes (CMA/12; membrane length, $2 \mathrm{~mm}$; diameter, $0.5 \mathrm{~mm}$; cutoff, $20 \mathrm{kDa}$; CMA, Stockholm, Sweden) were connected via a polyethylene tubing (FEP) to a microinfusion pump (CMA100) equipped with a liquid switch (CMA110). Electrophysiological recordings were carried under perfusion of artificial CSF (ACSF; composition in mM: $145 \mathrm{NaCl}, 2.7 \mathrm{KCl}, 1 \mathrm{MgCl}_{2}, 1.2$ $\mathrm{CaCl}_{2}, 0.1$ ascorbic acid, and 10 glucose, $\mathrm{pH}$ 7.4) and drugs. This procedure allowed recordings in intact cortical tissue and a simultaneous control of infusion of drugs.

Stimulation of the CA1/subicular region evokes a characteristic monosynaptic negativegoing field potential in the PFC with a peak latency of 18-21 msec. Once a correct signal was detected, we waited for $2 \mathrm{hr}$ perfusing the probe with ACSF to obtain a stable signal. Test pulses $(80-120 \mu \mathrm{sec})$ were delivered every $30 \mathrm{sec}$ at an intensity that evokes a $70 \%$ maximal response $(200-400 \mu \mathrm{A})$. High-frequency stimulation consisted of one or two series (6 min apart) of 10 trains $(250 \mathrm{~Hz}, 200 \mathrm{msec})$ at $0.1 \mathrm{~Hz}$, delivered at test intensity.

Data were analyzed using A/Dvance software (Mckellar Design). Postsynaptic potential amplitudes were expressed as a percentage change of the baseline and analyzed by ANOVA. Correct placement of the electrodes was confirmed by histology.

Drug delivery. Reverse microdialysis was used to apply DA drugs and forskolin in the PFC. In control animals, ACSF was continuously inf used at a flow rate of $2 \mu \mathrm{l} / \mathrm{min}$. In pharmacological groups, after a stable baseline (40 min), ACSF was replaced for $30 \mathrm{~min}$ (20 min before and 10 min after the first tetanus) by ACSF-containing drugs.

Microinjection through a cannula ( $80 \mu \mathrm{m}$ diameter) was used to apply locally the PKA inhibitor Rp-cAMPS. As for microdialysis experiments, two electrodes fixed to a cannula connected via a polyethylene tubing to a microinfusion pump (CMA100) allowed both electrophysiological recordings and drug infusion. Once a stable signal was obtained, baseline was recorded and ACSF or Rp-cAMPS delivered for $30 \mathrm{~min}(20 \mathrm{~min}$ before and $10 \mathrm{~min}$ after the first tetanus) at a flow rate of $0.013 \mu \mathrm{l} / \mathrm{min}$.

Drugs. The following drugs were stored as concentrated stock solutions and, before infusion, dissolved in ACSF (containing ascorbic acid) to achieve the experimental concentrations: (+)-SKF81297 (0.1-5 mM; Research Biochemicals, Natick, MA), R-(+)-SCH23390 (2-10 mM; Tocris), $S$-(-)-sulpiride (5-10 mM, Tocris), forskolin $(25 \mu \mathrm{M}$; Tocris), and Rp-cAMPS (300 $\mu$; Sigma). The effective extracellular concentrations of drugs, extrapolated from the relative recovery for DA drugs through the microdialysis probe, were estimated to be 10 -fold less than the concentrations within the probe.

On-line HPLC analysis of DA level in the PFC. Overall conditions for recording and microdialysis procedures were the same as described above. The implanted microdialysis probe (7-9\% recovery of DA in vitro) was continuously perfused with $\operatorname{ACSF}(2 \mu \mathrm{l} / \mathrm{min})$, and dialysates were analyzed for DA concentration by HPLC (EP-300; Eicom, Japan) with an electrochemical detector (ECD-300). Samples were injected every 10 min directly and automatically into the HPLC system with a polymeric reverse-phase C18 column (Eicompak CA-50DS; $4.6 \times 150 \mathrm{~mm}$ ) and a graft electrode (WE-3G) set at $450 \mathrm{mV}$ (vs $\mathrm{Ag} / \mathrm{AgCl}$ reference electrode). The mobile phase contained $0.1 \mathrm{M}$ phosphate, $55 \mathrm{mg} / \mathrm{l}$ sodium 1-octanesulfonate, $50 \mathrm{mg} / 1 \mathrm{EDTA}$, and $18 \% \mathrm{v} / \mathrm{v}$ methanol, $\mathrm{pH}$ 6.0. A stable dialysate DA concentration was usually obtained after a minimum of $2 \mathrm{hr}$ post-implantation of the probe. For data analysis, basal DA concentration was estimated from an average of three HPLC time points before tetanization. Electrophysiological hippocampal-PFC response was obtained during these HPLC periods.

\section{RESULTS}

\section{Experiment 1: effects of intra-PFC infusions of DA drugs on hippocampal-PFC LTP}

\section{Enhancement of hippocampal-PFC LTP by D1}

receptor activation

We first studied the effects of the D1 agonist SKF81297 infused for $30 \mathrm{~min}$ (20 min before tetanus, one series of high-frequency stimulation) in the PFC on hippocampal-PFC LTP (Fig. 2A). During the first 30 min after tetanus (left columns), LTP was significantly larger in the presence of SKF81297 at $0.1 \mathrm{~mm}(51.1 \pm$ $3.7 \%$ increase compared with baseline, $n=6, p<0.05)$ and $1 \mathrm{mM}$ $(70.4 \pm 10.1 \%, n=8, p<0.01)$ when compared with ACSF controls $(37.3 \pm 4.1 \%, n=7)$. Ninety minutes later, the enhancement of LTP was still present in rats infused with 1 mM SKF81297 (right columns and plotted graph; $59.0 \pm 7.7 \%, n=8, p<0.01$ ) when compared with ACSF controls $(22.8 \pm 4.9 \%, n=7)$. No effect on baseline responses was observed for all these doses. LTP in the presence of a high concentration of SKF81297 (5 mM) showed normal induction and maintenance when compared with ACSF controls (Fig. $2 A$, left columns; $37.3 \pm 4.1 \%, n=8, p>$ 0.05 ; right columns, $28.7 \pm 6.1 \%, n=8, p>0.05$ ). However, this concentration of D1 agonist slightly increased baseline values $(8.0 \pm 3.70 \%, p<0.05$, data not shown $)$ when compared with ACSF controls $(0.4 \pm 2.3 \%)$. These data demonstrate a clear facilitating effect of D1 agonist on LTP induction; they are consistent with our earlier findings showing a sustained increase in LTP amplitude when DA was infused before tetanus (Jay et al., 1996).

\section{Impairment of hippocampal-PFC LTP by D1 receptor blockade}

To confirm that D1 receptors activation affects hippocampalPFC LTP, we tested whether the D1 receptor antagonist SCH23390 had an effect on the induction of LTP. When SCH23390 was injected in the PFC in a similar way, we observed a dose-dependent decrease in the amplitude of hippocampalPFC LTP (Fig. 2B). In these experiments, a stronger protocol (two series) was applied in the hippocampus to induce a stable cortical LTP at least over $2 \mathrm{hr}$. During the first $30 \mathrm{~min}$ after tetanus (left columns), LTP amplitude was significantly lower at 2 $\mathrm{mm}(44.2 \pm 4.8 \%, n=7, p<0.05), 5 \mathrm{~mm}(31.5 \pm 5.3 \%, n=8, p<$ $0.001)$, and $10 \mathrm{~mm}(9.2 \pm 4.7 \%, n=8, p<0.001)$ when compared with ACSF controls $(61.1 \pm 5.2 \%, n=10)$. D1 receptor blockade persistently affected LTP during the subsequent recording time, and LTP was still impaired with $5 \mathrm{~mm}(26.6 \pm 3.6 \%, n=8, p<$ $0.01)$ and $10 \mathrm{~mm}(12.6 \pm 6.9 \%, n=8, p<0.001$; right columns and plotted graph) $2 \mathrm{hr}$ after tetanus when compared with ACSF controls $(50.0 \pm 4.6 \%, n=10)$. However, no further change was observed with the lowest dose, $2 \mathrm{~mm}$ (Fig. 2B, right columns; $49.1 \pm 7.5, n=7, p>0.05)$. No effect on baseline responses was observed for any of these doses. 


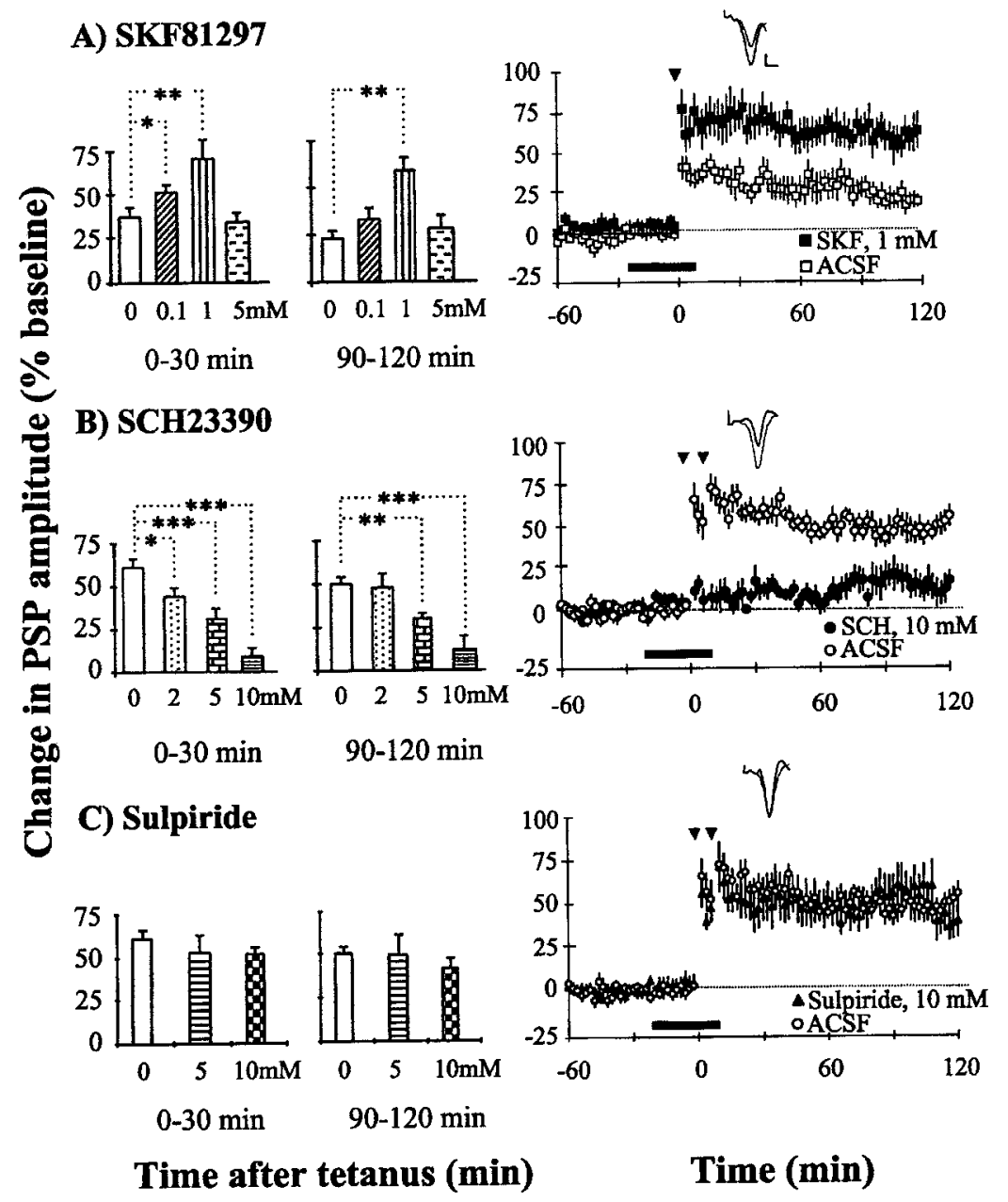

Figure 2. Dose-dependent effects of D1 but not D2 receptor drugs on hippocampal-PFC LTP. Left graphs, Columns represent mean \pm SEM of the normalized hippocampalPFC postsynaptic response amplitude during two stages (left columns, 0-30 min; right columns, 90-120 min) after tetanus. The first column on each graph represents ACSF controls, and the other columns represent the experimental groups. Right graphs, Changes in normalized hippocampalPFC postsynaptic response amplitude are plotted over time for the most effective dose in each experimental group. Each point represents mean \pm SEM of averaged responses to four test stimuli given at $30 \mathrm{sec}$ intervals. Values are expressed as percentage of change relative to baseline (40 $\mathrm{min}$ ). Tetanic stimulation (one or two series) is indicated by arrowheads. A, D1 agonist SKF81297 increases the amplitude of cortical LTP. Inf usion at $0.1(n=6)$ and $1 \mathrm{~mm}(n=$ 8 ) but not at $5 \mathrm{~mm}(n=6)$ evokes a significant enhancement of cortical potentiation during the first $30 \mathrm{~min}$ (left columns) when compared with ACSF controls $(n=7)$. Infusion of SKF81297 at $1 \mathrm{~mm}$ induces a persistent facilitation of cortical LTP (right column and plotted graph). B, D1 antagonist SCH23390 impairs hippocampal-PFC LTP. Infusion at 2 $(n=7), 5(n=8)$, and $10 \mathrm{~mm}(n=8)$ produces a significant dose-dependent decrease of cortical potentiation in the first 30 min (left columns) when compared with ACSF controls $(n=10)$. A sustained decrease in LTP amplitude is observed with the highest doses of antagonist 5 and $10 \mathrm{~mm}$; right column and plotted graph). C, D2 antagonist sulpiride does not affect hippocampal-PFC LTP. No significant effect is observed at $5(n=6)$ or $10 \mathrm{~mm}(n=8)$. Representative averaged waveforms (four) on each graph were taken 30 min after induction of LTP: ACSF controls (shaded), most effective dose in the experimental group (dark). Calibration: $0.2 \mathrm{mV}, 10 \mathrm{msec}$. Levels of significance, drug versus control: ${ }^{*} p<0.05,{ }^{* *} p<0.01,{ }^{* *} p<0.001$.

\section{Hippocampal-PFC LTP is not affected by blockade of D2 receptor}

Using a similar protocol as for SCH23390, we then examined whether the D2 antagonist sulpiride could affect hippocampalPFC LTP. Figure $2 C$ shows that sulpiride had no effect on either the induction (left columns, $5 \mathrm{mM}$ : $52.6 \pm 4.4 \%, n=6, p>0.05$; $10 \mathrm{~mm}$ : $53.1 \pm 10.3 \%, n=8, p>0.05)$ or the maintenance of LTP (right columns and plotted graph, $5 \mathrm{~mm}$ : $41.7 \pm 6.4 \%, n=6, p>$ 0.05 ; 10 mм: $49.5 \pm 11.2 \%, n=8, p>0.05$ ) when compared with ACSF controls.

\section{Experiment 2: changes in endogenous DA in the PFC during hippocampal-PFC LTP}

The reduction in hippocampal-PFC LTP by a D1 antagonist suggested that DA may be released during tetanus and therefore enhanced LTP. As shown in Figure 3, perfusion of ACSF in the PFC through microdialysis probes combined with recording of postsynaptic potential allowed us to measure the dialysate concentration of cortical DA (every $10 \mathrm{~min}$ ) before and after tetanic stimulation of the hippocampus, by using on-line HPLC. Tetanic stimulation (two series) was applied only when the level of DA in the PFC was stable for at least $30 \mathrm{~min}$. The mean basal level of DA was $80.2 \pm 19.9 \mathrm{fmol} / 10 \mathrm{~min}$ and a significant increase in cortical DA level compared with baseline was observed immediately after tetanus and for $20 \mathrm{~min}$ after the first tetanus (respectively, $126.7 \pm 19.3 \%, p<0.05$, and $113.3 \pm 9.5, p<0.05, n=7$ ).

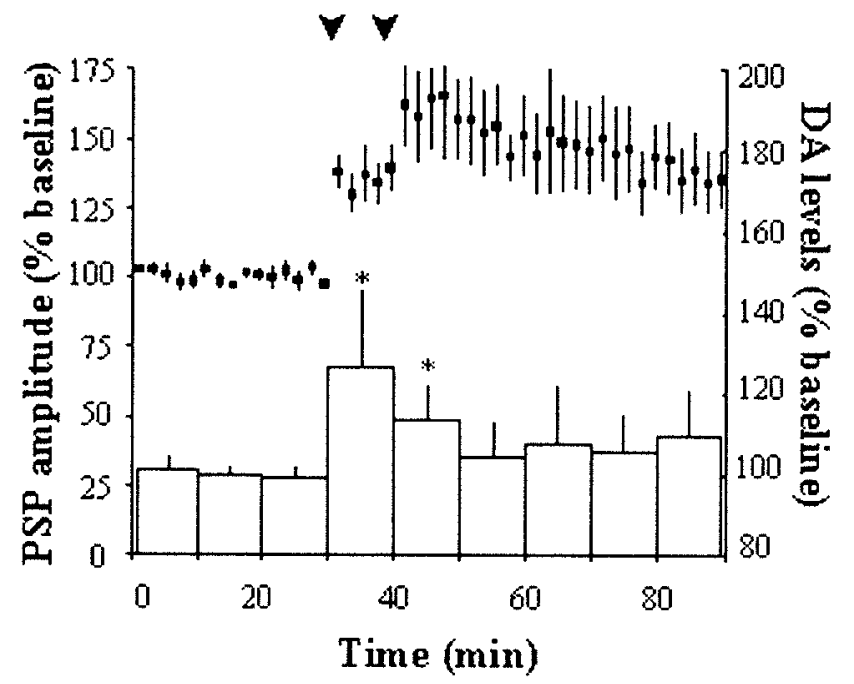

Figure 3. Evoked changes in DA content in the PFC by hippocampal tetanic stimulation. Top graph, Changes in the amplitude of cortical postsynaptic potential showing hippocampal-PFC LTP in rats continuously perfused with ACSF $(n=7)$. Each point represents mean \pm SEM of averaged responses to four test stimuli given at $30 \mathrm{sec}$ intervals. Values are expressed as percentage of change relative to baseline (30 $\mathrm{min})$. Tetanic stimulation is indicated by arrowheads. Bottom histogram, DA level in the PFC before and after hippocampal tetanic stimulation. Data are shown as percentages of control values measured during baseline (mean \pm SEM). LTP increases DA level to 130 and $120 \%(p<0.05)$ of baseline during the first $20 \mathrm{~min}$ after tetanus. 


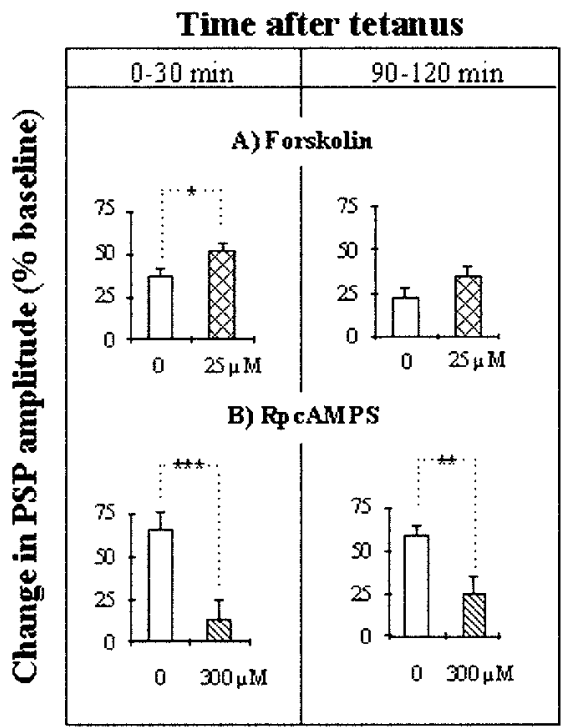

Figure 4. Modulation of hippocampal-PFC LTP amplitude by drugs directly affecting the AC-cAMP-PKA pathway. The representation is similar to left graphs in Figure 2. A, The AC activator forskolin $(25 \mu \mathrm{M}$, $n=7)$ enhances the amplitude of LTP during 30 min after tetanus $(p<$ 0.05 , left columns), whereas no significant effect is observed at a later time (right columns). B, The PKA inhibitor Rp-cAMPS (300 $\mu \mathrm{M}, n=7)$ decreases dramatically cortical LTP amplitude during at least $2 \mathrm{hr}$ after tetanus.

\section{Experiment 3: role of cAMP and PKA in hippocampal-PFC LTP}

In view of the preceding results, DA could act through the D1 receptor cascade, involving activation of a G-protein, adenylyl cyclase (AC), a postsynaptic increase in cAMP levels, and a consequent enhanced activation of PKA. Indeed, a rapid, NMDA-dependent activation of cytosolic PKA was found within minutes after induction of LTP in the hippocampal-PFC pathway in vivo (Jay et al., 1998), thus suggesting an involvement of the cAMP-PKA signal transduction cascade in the early phases of cortical LTP. To test whether activation of the AC-cAMP-PKA cascade mimicked the SKF81297 effects, we applied an activator of AC, forskolin, in the PFC through the microdialysis probe. As with DA drugs, forskolin was infused during $30 \mathrm{~min}(20 \mathrm{~min}$ before tetanus, one series of high-frequency stimulation). Figure $4 A$ shows that forskolin $(25 \mu \mathrm{M})$ increased significantly early LTP (left columns, $51.9 \pm 5.0 \%, n=7, p<0.05)$ but not late LTP (right columns, $34.6 \pm 5.9 \%, n=7, p>0.05)$ when compared with ACSF controls (same as for SKF81297 group). No effect was observed on baseline.

Knowing the involvement of AC in cortical LTP, we examine whether blocking PKA by Rp-cAMPS would affect hippocampal-PFC LTP. Rp-cAMPS $(300 \mu \mathrm{M})$ injected locally in the PFC before tetanus (30 min duration, 20 min before tetanus; two series of high-frequency stimulation), severely attenuated LTP (12.7 \pm $11.7 \%, n=7, p<0.001$ ) during the first $30 \mathrm{~min}$ after tetanus (Fig. $4 B$, left columns) when compared with ACSF controls (67.2 \pm $10.3 \%, n=7)$. The reduction in amplitude persisted throughout the recording time and was still significant $2 \mathrm{hr}$ after tetanus (Fig. $4 B$, right columns, $25.3 \pm 9.6 \%, n=7, p<0.01)$ when compared with ACSF controls $(59.7 \pm 5.8 \%, n=7)$. No significant effect on baseline was detected.

\section{DISCUSSION}

The data presented here demonstrate for the first time the importance of D1 receptor as a mediator contributing to the occurrence of an NMDA receptor-dependent LTP at hippocampalPFC synapses in vivo, suggesting that DA is a crucial executive neurotransmitter in the PFC. First, D1 but not D2 receptor blockade prevented the full development of cortical LTP; second, stimulation of D1 receptors produced a sustained enhancement of LTP. These findings are consistent with and extend those of previous studies in which local exogenous DA inf usion in the PFC or increase in endogenous cortical DA caused by a transient stimulation of the VTA produced a long-lasting enhancement in the magnitude of hippocampal-PFC LTP (Jay et al., 1996; Gurden at al., 1999).

D1 receptors appear to be crucial for a role of DA in this cortical LTP. In SKF81297-inf used animals, the enhancement of LTP is strong and persistent at $1 \mathrm{mM}$. However, when injected at $5 \mathrm{~mm}$, this D1 agonist does not further increase LTP amplitude compared with controls, suggesting that overstimulation of D1 receptors disrupts the facilitatory effects of DA on synaptic plasticity in the PFC. These results are in favor of a stepwise control of LTP according to the amount of D1 receptor stimulation and suggest an optimal D1 receptor activation for proper hippocampal-PFC LTP expression. It is interesting to note that similar findings have been shown in the monkey for the modulation of delay-period activity in PFC neurons (Williams and GoldmanRakic, 1995). Conversely, for the D1 antagonist, a concentrationdependent inhibition occurred at the early stages of cortical LTP, and a threshold concentration $(5 \mathrm{~mm})$ to get long-lasting impairment (at least for $2 \mathrm{hr}$ ) was observed. These results indicate that not only early but also later stages of hippocampal-PFC LTP are strongly dependent on D1 receptor activation.

The modulatory effects of DA in the hippocampus have been associated with the late long-lasting, protein synthesis-dependent phase of LTP at the Schaffer collateral-CA1 synapses (Frey et al., 1990; Huang and Kandel, 1995), although controversial results have shown that D1 receptors are essential for the early phase (Otmakhova and Lisman, 1996). Interestingly, a recent in vivo study (Swanson-Park et al., 1999) reported differential effect of DA on two NMDA-dependent LTPs within the hippocampus: D1 receptors were shown to be involved in the maintenance of CA1 LTP, whereas these receptors did not modulate dentate gyrus LTP. If we compare these results to our present data, the major difference between CA1 and hippocampal-PFC in vivo LTPs appears to be the short onset of the D1 antagonist effects. The spatial distribution of DA fibers and D1 receptors as shown in the monkey (Smiley et al., 1994) but not in the rat should help in understanding these different DA effects in hippocampal and cortical LTPs. To our knowledge, only one study on CA1 slices using $\left[{ }^{14} \mathrm{C}\right] \mathrm{DA}$ has shown that tetanization produces a significantly enhanced release of DA (Frey et al., 1990). In the present study, we have also measured a significant increase in DA release in the PFC during tetanic stimulation of the ventral hippocampus, which suggests a direct role of DA in the induction of cortical LTP. One possible explanation could be that tetanized prefrontal neurons more strongly activate the VTA cells that they project to, increasing DA release in the PFC. However, the close proximity of hippocampal and DA terminals in the PFC targeting the same dendrites in deep layers of the prelimbic area (Carr and Sesack, 1996) are in favor of a local interplay. Given the fact that the increase in DA levels in the PFC occurs mainly during tetanization that activates NMDA receptors (Jay et al., 1995), the putative existence of heterosynaptic NMDA receptors on DA presynaptic terminals is suggested, and the following hypothetical model of DA-glutamate interactions is proposed: during high-frequency stimulation delivered to excitatory synapses, NMDA receptors are activated both on postsynaptic pyramidal neurons and mesoprefrontal terminals in the PFC, and as a consequence extracellular DA is increased. Hence, DA acting through postsynaptic D1 receptors modulates powerfully NMDA receptor activation, which triggers LTP. This hypothesis is supported by previous studies showing (1) an NMDA-dependent DA release (Feenstra et al., 1995), (2) an enhancement of NMDA-mediated currents by 
DA on pyramidal cells (Cepeda et al., 1992), and (3) an impairment of NMDA-dependent LTP in rats with decreased DA levels (Gurden et al., 1999), and these NMDA-DA interactions have also been reported in the striatum (Cepeda and Levine, 1998; Centonze et al., 1999). In addition, ultrastructural studies looking at synaptic localization of NMDA receptors in the cerebral cortex have already shown the existence of both homosynaptic receptors on asymmetrical synapses and heterosynaptic receptors on symmetrical synapses (Petralia et al., 1994; DeBiasi et al., 1996) but until now, a study dealing with the synaptic localization of both DA and glutamatergic receptors in the PFC is lacking.

D1 receptors stimulate AC and provoke an elevation of intracellular cAMP levels, which in turn activates PKA. Here, we report a transient facilitation of hippocampal-PFC potentiation by the $\mathrm{AC}$ activator forskolin, indicating that $\mathrm{AC}$ is implicated in the early stages of cortical LTP. These results are comparable with the transient facilitation of LTP observed with a slight activation of D1 receptors (SKF81297, $0.1 \mathrm{~mm}$ ). In addition, blocking the downstream PKA cascade by Rp-cAMPS injection in the PFC resulted in a dramatic impairment of cortical LTP, comparable with the strong decrease observed with the D1 antagonist. This latter observation together with our previous report showing a rapid NMDA-dependent increase in PKA activity during induction of hippocampal-PFC LTP (Jay et al., 1998) strongly suggest that AC-cAMP-PKA pathway plays a key role in the early stages of cortical LTP. PKA is known to upregulate NMDA receptor activation by phosphorylation (Blank et al., 1997), therefore through activation of PKA, D1 receptors stimulation could control the excitatory synaptic strength in the PFC. Additional studies using a wider dose range of drugs affecting the AC-cAMP-PKA pathway applied with DA drugs are needed to assess this hypothesis.

Behavioral and physiological studies suggested that normal cognitive performance occurs within an optimal range of DA levels and D1 receptor activation in the PFC (Williams and Goldman-Rakic, 1995; Zahrt et al., 1997). Here we brought evidence at the synaptic level of a gating function of D1 receptors on a specific excitatory input to the PFC arising from the hippocampus. Assuming that LTP is a candidate for cellular information storage, the present results can be correlated with the D1 receptor-dependent control of hippocampal information processing in the PFC previously demonstrated in rats by an impairment in a spatial delayed task in which ventral hippocampal inactivation was combined with PFC infusion of SCH23390 (Seamans et al., 1998). The hippocampal-PFC pathway is also involved in nonspatial events and novelty detection (Knight and Nakada, 1998; Izaki et al., 2000). Therefore, to clarify hippocampal information sent to the PFC, it would be essential to identify at the same time, cortical DA activity patterns in such behavioral paradigms.

\section{REFERENCES}

Blank T, Nijholt I, Teichert U, Kügler H, Behersing H, Fienberg A, Greengard P, Spiess J (1997) The phosphoprotein DARPP-32 mediates cAMP-dependent potentiation of striatal $N$-methyl-D-aspartate responses. Proc Natl Acad Sci USA 94:14589-14864.

Burette F, Jay T, Laroche S (1997) Reversal of LTP in the hippocampal afferent fiber system to the prefrontal cortex in vivo with low-frequency patterns of stimulation that do not produce LTD. J Neurophysiol 78:1155-1160.

Carr DB, Sesack SR (1996) Hippocampal afferents to the rat prefrontal cortex: synaptic targets and relation to dopamine terminals. J Comp Neurol 369:1-15.

Centonze D, Gubellini P, Picconi B, Calabresi P, Giacomini P, Bernardi G (1999) Unilateral dopamine denervation blocks corticostriatal LTP. J Neurophysiol 82:3575-3759.

Cepeda C, Levine M (1998) Dopamine and $N$-methyl-D-aspartate receptor interactions in the neostriatum. Dev Neurosci 20:1-8.

Cepeda C, Radisavljevic Z, Peacock W, Levine MS, Buchwald NA
(1992) Differential modulation by dopamine of responses evoked by excitatory amino acids in human cortex. Synapse 11:330-441.

DeBiasi S, Minelli A, Melone M, Conti F (1996) Presynaptic NMDA receptors in the neocortex are both auto- and heteroreceptors. NeuroReport 7:2773-2776.

Feenstra M, van der Weij W, Botterblom M (1995) Concentrationdependent dual action of locally applied $N$-methyl-D-aspartate on extracellular dopamine in the rat prefrontal cortex in vivo. Neurosci Lett 201:175-178.

Floresco SB, Seamans JK, Philips AG (1997) Selective roles for hippocampal, prefrontal cortical, and ventral striatal circuits in radial-arm maze tasks with or without a delay. J Neurosci 17:1880-1890.

Frey U, Schroeder H, Matthies H (1990) Dopaminergic antagonists prevent long-term maintenance of posttetanic LTP in the CA1 region of rat hippocampal slices. Brain Res 522:69-75.

Gaspar P, Bloch B, Le Moine C (1995) D1 and D2 receptor gene expression in the rat frontal cortex: cellular localization in different classes of efferent neurons. Eur J Neurosci 7:1050-1063.

Granon S, Passetti F, Thomas K, Dalley J, Everitt B, Robbins T (2000) Enhanced and impaired attentional performance after infusion of D1 dopaminergic receptor agents into the prefrontal cortex. J Neurosci 20:1208-1215.

Gurden H, Tassin JP, Jay TM (1999) Integrity of the mesocortical DA system is necessary for complete expression of in vivo hippocampalprefrontal cortex long-term potentiation. Neuroscience 94:1019-1027.

Huang Y, Kandel E (1995) D1/D5 receptor agonists induce a proteinsynthesis-dependent late potentiation in the CA1 region of the hippocampus. Proc Natl Acad Sci USA 92:2446-2450.

Izaki Y, Hori K, Nomura M (2000) Disturbance of rat lever-press learning by hippocampo-prefrontal cortex disconnection. Brain Res 860:199-202.

Jay TM, Burette F, Laroche S (1995) NMDA receptor-dependent LTP in the hippocampal afferent fibre system to the prefrontal cortex in the rat. Eur J Neurosci 7:247-250.

Jay TM, Burette F, Laroche S (1996) Plasticity of the hippocampalprefrontal cortex synapses. J Physiol (Paris) 90:367-366.

Jay TM, Gurden H, Yamaguchi T (1998) Rapid increase in PKA activity during LTP in the hippocampal afferent fiber system to the prefrontal cortex in vivo. Eur J Neurosci 10:3302-3306.

Jung M, Qin Y, McNaughton B, Barnes C (1998) Firing characteristics of deep layer neurons in prefrontal cortex in rats performing spatial working memory tasks. Cereb Cortex 8:437-450.

Knight R, Nakada T (1998) Cortico-limbic circuits and novelty: a review of EEG and blood flow data. Rev Neurosci 9:57-70.

Lu X, Churchill L, Kalivas P (1997) Expression of D1 receptor mRNA in projections from the forebrain to the ventral tegmental area. Synapse 25:205-214

Otmakhova NA, Lisman JE (1996) D1/D5 dopamine receptors activation increases the magnitude of early long-term potentiation at CA1 hippocampal synapses. J Neurosci 16:7478-7486.

Petralia R, Yokotani N, Wenthold R (1994) Light and electron microscope distribution of the NMDA receptor subunit NMDAR1 in the rat nervous system using a selective anti-peptide antibody. J Neurosci 14:667-696.

Seamans JK, Floresco SB, Phillips AG (1998) D1 receptor modulation of hippocampal-prefrontal cortical circuits integrating spatial memory with executive functions in the rat. J Neurosci 18:1613-1621.

Smiley JF, Levey AI, Ciliax BJ, Goldman-Rakic PS (1994) D1 dopamine receptor immunoreactivity in human and monkey cerebral cortex: predominant and extrasynaptic localization in dendritic spines. Proc Natl Acad Sci USA 91:5720-5724.

Swanson-Park J, Coussens C, Mason-Parker S, Raymond C, Hargreaves E, Dragunow M, Cohen A, Abraham W (1999) A double dissociation within the hippocampus of dopamine D1/D5 receptor and betaadrenergic receptor contributions to the persistence of long-term potentiation. Neuroscience 92:485-497.

Takita M, Izaki Y, Jay TM, Kaneko H, Suzuki S (1999) Induction of stable long-term depression in vivo in the hippocampal-prefrontal cortex pathway. Eur J Neurosci 11:4145-4148.

Williams GV, Goldman-Rakic PS (1995) Modulation of memory fields by dopamine D1 receptors in prefrontal cortex. Nature 376:572-575.

Yang C, Seamans J, Gorelova N (1999) Developing a neuronal model for the pathophysiology of schizophrenia based on the nature of electrophysiological actions of dopamine in the prefrontal cortex. Neuropsychopharmacology 21:161-194.

Zahrt J, Taylor JR, Mathew RG, Arnsten AFT (1997) Supranormal stimulation of D1 dopamine receptors in the rodent prefrontal cortex impairs spatial working memory performance. J Neurosci 17:85288535. 